\title{
84. DATA REPORT: ELECTRICAL RESISTIVITY EXPERIMENT IN THE YAMATO BASIN ${ }^{1}$
}

\author{
Yozo Hamano, ${ }^{2}$ Hisashi Utada, ${ }^{3}$ and Keir Becker ${ }^{4}$
}

\begin{abstract}
During Leg 128, a new electrical resistivity experiment was conducted at Site 794 in the Japan Sea. The experiment utilizes as a source a vertical current dipole that extends from the sea surface to the bottom, and vertical electric fields caused by the source current were measured in a hole drilled into the sediment layer. Results of this experiment and the Schlumberger standard logging data obtained during Legs 127 and 128 revealed a highly conductive structure in the top several kilometers of the oceanic crust in the Yamato Basin.
\end{abstract}

\section{INTRODUCTION}

Electrical resistivity is one of the most sensitive parameters for understanding the physical state of the crust and the upper mantle. The resistivity reflects the content and the connectivity of seawater in the oceanic crust and the top part of the upper mantle. Deeper temperature and the melting state in the mantle can also be inferred from the resistivity measurement.

Over the past two decades, natural electromagnetic disturbances have been measured at seafloor and have been used to determine the electrical resistivity structure of the oceanic plate to a depth of about $300 \mathrm{~km}$ (Cox et al., 1970; Filloux, 1981; Yukutake et al., 1983). These observations revealed the existence of a high conductivity layer (HCL) at depths of 60 to $200 \mathrm{~km}$ under the oceanic lithosphere. Low-frequency magnetotelluric soundings (MTS) or geomagnetic deep soundings (GDS) have been used for interpretation of the data. These measurements are insufficient for the shallow part of the lithosphere, since the short-period signals, shorter than $10 \mathrm{~min}$, are highly attenuated by the shielding effect of seawater.

For the shallowest part of the oceanic crust, electrical resistivity has been measured in DSDP/ODP holes. Standard Schlumberger logging and a large-scale resistivity experiment (Francis, 1982; Becker, 1984) are main techniques for the resistivity measurement in the drill holes. Although these methods can give high resolution of the resistivity structure, logging depth is limited to the depth of the holes. To obtain the resistivity structure at intermediate depths under the seafloor, various types of controlled source methods have been invented (Cox et al., 1981; Edwards et al., 1981; Nobes et al., 1986). Among them, the magnetometric off-shore electrical sounding (MOSES) method uses a vertical current source extending from the sea surface to the bottom and observes an azimuthal component of the magnetic field at seafloor. The method has been successfully conducted at two sites in the northern Juan de Fuca Ridge, and the resistivity structure to a depth of $2 \mathrm{~km}$ has been obtained (Nobes et al., 1986). Compared to a horizontal source, the vertical source is ineffective for transmitting signals to the deep interior, but the mobility of the transmitter enables quick determination of the shallow structure. The sounding depth of the MOSES method is limited by the resolution of the magnetometer and the depth of seawater. At present the resolution of the magnetic field measurement is about $0.1 \mathrm{nT}$ and the maximum sounding depth is a few kilometers.

\footnotetext{
' Tamaki, K., Suyehiro, K., Allan, J., McWilliams, M., et al., 1992. Proc. ODP, Sci. Results, 127/128, Pt. 2: College Station, TX (Ocean Drilling Program).

${ }^{2}$ Geophysical Institute, Faculty of Science, University of Tokyo, Tokyo 113, Japan.

${ }^{3}$ Earthquake Research Institute, University of Tokyo, Tokyo 113, Japan.

${ }^{4}$ Rosenstiel School of Marine and Atmospheric Science, Division of Marine Geology and Geophysics, Miami, FL 33149-1098, U.S.A.
}

Around the Japanese islands, we have been continuing the electromagnetic measurements at seafloor since 1981, and extensive land measurements on the Japanese islands have also been made by the Electrical Resistivity Study Group of Japan. These measurements revealed the electrical resistivity structure under the three oceanic plates around the Japanese islands (Yukutake et al., 1983; Utada et al, 1986). The resistivity structure under the Pacific and Philippine Sea plates indicates the normal nature of these plates. HCL exists at depths of 150 and $30 \mathrm{~km}$ under the Pacific and the Philippine Sea plates, respectively. These depths are consistent with the age of the respective plate. On the other hand, the Japan Sea Plate is quite different. The HCL is not observed under the Japan Sea, and the conductivity in the upper mantle is as low as about $0.001 \mathrm{~S} / \mathrm{m}$ down to the depth of about $100 \mathrm{~km}$. This result seems strange considering the estimated young age of the Japan Sea (30-10 Ma) and the high heat-flow values that have been extensively observed in the Japan Sea.

Considering the importance of the electrical resistivity structure under the Japan Sea in relation to the origin of the Japan Sea, we performed magnetotelluric (MT) measurements in the Yamato Basin. Results also indicate the resistive structure under the Yamato Basin. However, because of the absence of information about the shallow electrical structure in the Yamato Basin, results are not conclusive. We may need the thickness of the resistivity structure down to a depth of several kilometers to clarify the overall structure under the Japan Sea.

During Leg 128, a new electrical resistivity experiment was conducted to obtain the resistivity structure for the top several kilometers under the Yamato Basin. Here, we report the results of that experiment. The electrical resistivity structure of the crust and the upper mantle under the Yamato Basin inferred from this experiment and the MT measurements at seafloor will be presented elsewhere.

\section{EXPERIMENT AND RESULTS}

As explained in Ingle, Suyehiro, Breymann, et al. (1990), a resistivity experiment was conducted during Leg 128 by using Hole $794 \mathrm{E}\left(39.22^{\circ} \mathrm{N}, 133.87^{\circ} \mathrm{E}\right)$ as a sensor. The method is a modified version of the MOSES method. This experiment uses a vertical current dipole that extends from the sea surface to the bottom, and the vertical electric fields caused by the current signal were observed in the hole. Two ships were employed in this experiment; signals were generated by the Kaikomaru- 5 and real-time measurements of the electric potential were performed on board the JOIDES Resolution. The depth variation of the electrical resistivity is obtained by repeating the measurement at different source-receiver distances.

The sensor for this experiment consists of a seven-wire insulated cable with silver-silver chloride electrodes. The sensor cable was attached to the end of the standard logging cable and lowered through the drill pipe into the hole. The position of the electrodes in Hole 794E is illustrated in Figure 1. In the experiment, electric potential differences 
between two pairs of electrodes, Pairs 3 and 5 and 2 and 4 , were measured as channels 1 and 2. Distances between the electrode pairs for the two channels are 140 and $220 \mathrm{~m}$, respectively. On board the JOIDES Resolution, the wires connected to these electrodes were fed to two input channels of a YEW3655 analyzing recorder through a pre-amplifier with a gain of 100 . The recorder converts the two channel input signals to digital data and can stack up to 256 times.

During the experiment, measurements were conducted at eight positions of the shooting ship, where four stations were aligned along the direction of the extension of the Yamato Basin $\left(\mathrm{N} 60^{\circ} \mathrm{E}\right)$, and the other four along the nearly perpendicular direction. The distance and the direction of the eight sites relative to the hole as well as the observed electric field for the two pairs of electrodes are listed in Table 1.

In the measurements, a serious noise source was the disturbance due to the movement of the bottom part of the drill pipe. Although stacking of data reduces noise level, the pre-amplifier could not be used for the first two stations (Stations 1 and 2). Hence, the position of the drill pipe was adjusted during the first part of the experiment. Originally, the depth of the bottom of the drill pipe was $74.7 \mathrm{mbsf}$. After the measurement at Station 1, the drill pipe was pulled up to a depth of 65.7 mbsf. Measurements at Station 2 indicate a reduction of noise. However, the pre-amplifier was still unusable. The drill pipe was pulled up again after Station 2 to a depth of $57 \mathrm{mbsf}$. This adjustment further reduced the noise level and permitted the use of the pre-amplifier for measurements.

In the following discussion, the source current and the observed signals at every station are discussed separately. Because the signals of channel 1 were less noisy than those of channel 2 and were observed at all the stations, the channel 1 data for each station are compared first.

\section{Current Source}

The current signal voltage was supplied by a transmitter on board the Kaikomaru-5 (Fig. 2). The transmitter consists of a direct current (DC) power source and a switch box. During the measurement, the current signal was monitored and recorded on board ship with the same system as that used for potential measurements. Sampling rate for the recording was $10 \mathrm{~ms}$. The positive and the negative constant currents (with a duration of $1 \mathrm{~s}$ ) were supplied, alternately separated by a 1-s quiet time. Figure $2 \mathrm{~A}$ shows the actual current signal. The period of 1 cycle of the signal is $4 \mathrm{~s}$. As we tried to maximize the intensity of the current source, some offset current exists during the quiet time, and it causes a step change at the time of polarity switch. The amplitude of the constant current is about $23 \mathrm{~A}$, which is slightly higher than the expected current of $20 \mathrm{~A}$. To reduce noise and to gain a stability of the measurement, the observed signal was stacked by 64 to 256 times, and two anti-phase time series were generated by dividing the original signal at a middle point $(2 \mathrm{~s})$. Finally, the two anti-phase signals were mutually subtracted to obtain the final data. Results of this procedure applied on the current signal are shown in Figure 2B.

Amplitude of the signals is obtained by applying the least-squares fit of a cosine curve with a 4-s period. The fitted curve for the source current is also shown in Figure 2B. This procedure is applied to all of the observed signals to obtain the signal amplitude.

\section{Channel 1 (Electrode Pairs 3 and 5)}

\section{Stations 1 and 8}

Results of the measurements at Stations 1 and 8 are shown in Figure 3. Distances of these two stations nearest the hole are 0.94 and $0.85 \mathrm{~km}$, respectively. The first measurement of the experiment was performed at Station 1. During this measurement, the bottom of the drill pipe (see Fig. 1) was 74.7 mbsf, and the distance between the top electrode (No. 1) and the bottom of the drill pipe was about $14 \mathrm{~m}$. This closeness and the sea condition caused a high noise level (as shown in Fig. 3) that precluded the use of the pre-amplifier. The noise level decreases with the distance of the electrodes from the bottom of
Table 1. Summary of the observed vertical electrical field (Ez).

\begin{tabular}{ccccccc}
\hline Station & $\begin{array}{c}\text { Distance } \\
(\mathrm{km})\end{array}$ & $\begin{array}{c}\text { Direction } \\
\left({ }^{\circ} \mathrm{E}\right)\end{array}$ & $\begin{array}{c}\text { Ez }(\mathrm{Ch} .1) \\
(\mathrm{nV} / \mathrm{m})\end{array}$ & $\begin{array}{c}\text { Error } \\
(\mathrm{nV} / \mathrm{m})\end{array}$ & $\begin{array}{c}\text { Ez (Ch. 2) } \\
(\mathrm{nV} / \mathrm{m})\end{array}$ & $\begin{array}{c}\text { Error } \\
(\mathrm{nV} / \mathrm{m})\end{array}$ \\
\hline 1 & 0.94 & $\mathrm{~N} 74$ & 60.4 & 8.9 & & \\
2 & 2.41 & $\mathrm{~N} 70$ & 54.4 & 1.1 & & \\
3 & 4.07 & $\mathrm{~N} 58$ & 36.1 & 0.9 & & \\
4 & 6.29 & $\mathrm{~N} 59$ & 2.3 & 0.7 & 23.1 & 3.0 \\
5 & 6.62 & $\mathrm{~N} 330$ & 13.9 & 0.9 & 20.8 & 2.8 \\
6 & 3.89 & $\mathrm{~N} 325$ & 27.6 & 0.9 & 39.3 & 1.5 \\
7 & 1.90 & $\mathrm{~N} 330$ & 67.9 & 0.9 & 94.5 & 2.2 \\
8 & 0.85 & $\mathrm{~N} 325$ & 228.1 & 2.0 & 321.3 & 2.7 \\
\hline
\end{tabular}

the drill pipe. At Station 1, channel 2 (electrode Pairs 2 and 4) was too noisy, and only the channel 1 measurement was conducted without pre-amplifier.

Least-squares fit of a cosine curve gives an amplitude of the signal as about $8.56 \mathrm{mV}$. The fitted cosine curve is also shown in Figure 3, which indicates that the estimated amplitude is unreliable at this station. After the measurement at Station 1, the drill pipe was raised to 65.7 mbsf during the Kaikomaru-5 was moving to the next station.

The measurement at Station 8 was conducted as the last station. The signal was large and clear, and the cosine curve fitted well to the observed signal. The amplitude obtained by the curve fitting has a value of $31.94 \mathrm{mV}$, with a standard error of $0.28 \mathrm{mV}$. Pre-amplifier was used at this station, and the noise level was as small as about $1 \mathrm{mV}$ at input level. The apparent low amplitude at Station 1 may have been caused by the high noise level at the station.

\section{Stations 2 and 7}

The distances of these stations from the sensor are 2.41 and $1.90 \mathrm{~km}$, respectively (Fig. 4). At Station 2, still the noise did not allow the use of the pre-amplifier, and the signal level was much smaller than that at Station 1. But, the sinusoidal signal is clearly observed at this site for channel 1 . The amplitude of the fitted cosine curve is $7.61 \mathrm{mV}$, with the standard error of $0.16 \mathrm{mV}$. In this site, number of stacks is 64 . At Station 7, the cosine curve fit the observed signal well, and the amplitude of the curve is $9.50 \mathrm{mV}$, which is slightly higher than that at Station 2, probably reflecting the shorter distance between the source and the receiver.

\section{Stations 3 and 6}

The second trip of the drill pipe permitted the use of the pre-amplifier after Station 2 (Fig. 5). At Station 3, 64-fold stacking was done to obtain the signal. The distance of Station 3 is $4.07 \mathrm{~km}$. The least-squares fit indicates a signal amplitude of $5.06 \mathrm{mV}$. At Station 6 , slightly smaller amplitude of $3.86 \mathrm{mV}$ was detected, although the distance of Station 6 is $3.89 \mathrm{~km}$ from the observation point.

\section{Stations 4 and 6}

These two stations were the farthest ones in this experiment and had a distance of about $7 \mathrm{~km}$ (Fig. 6). The vertical scale of the figures in Figure 6 is the same for both stations. Apparently, the signal amplitude at Station 4 is much smaller than that at Station 5. The least-squares fit of cosine curves gives amplitudes of 0.32 and $1.95 \mathrm{mV}$ for Stations 4 and 5 , respectively.

\section{Channel 2 (Electrode Pairs 2 and 4)}

Figure 7 shows the observed channel 2 signals for Stations 4 through 8 . For the first three stations (1-3), this channel was not measured because of the high noise level caused by the disturbances of the drill pipe. The amplitude of the signals decreases with the increase of the source-receiver distance. Note that the signal ampli- 


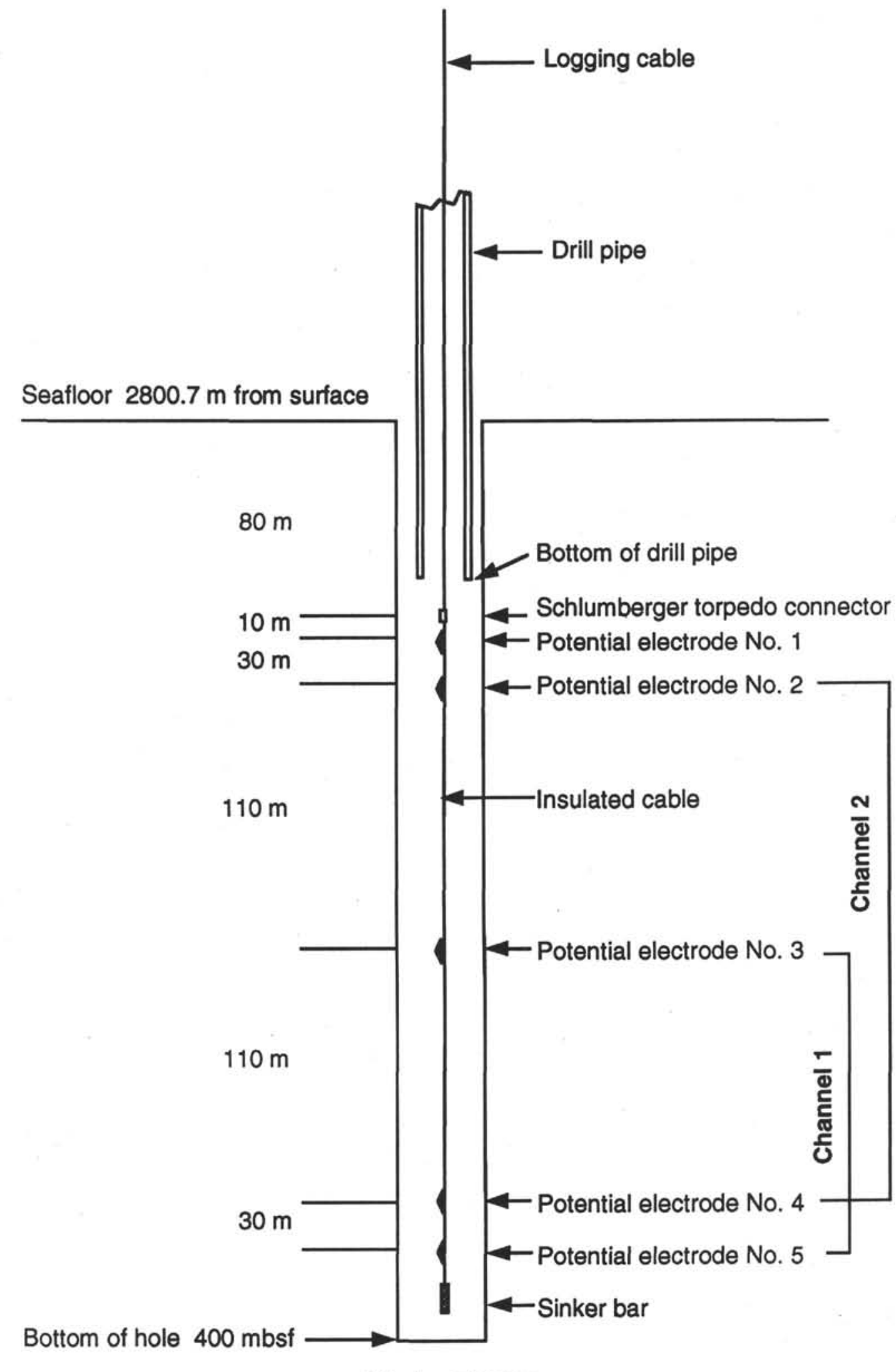

Hole 794E

Figure 1. Configuration of the sensor cable and the electrodes in Hole 794E during the resistivity experiment. 
A
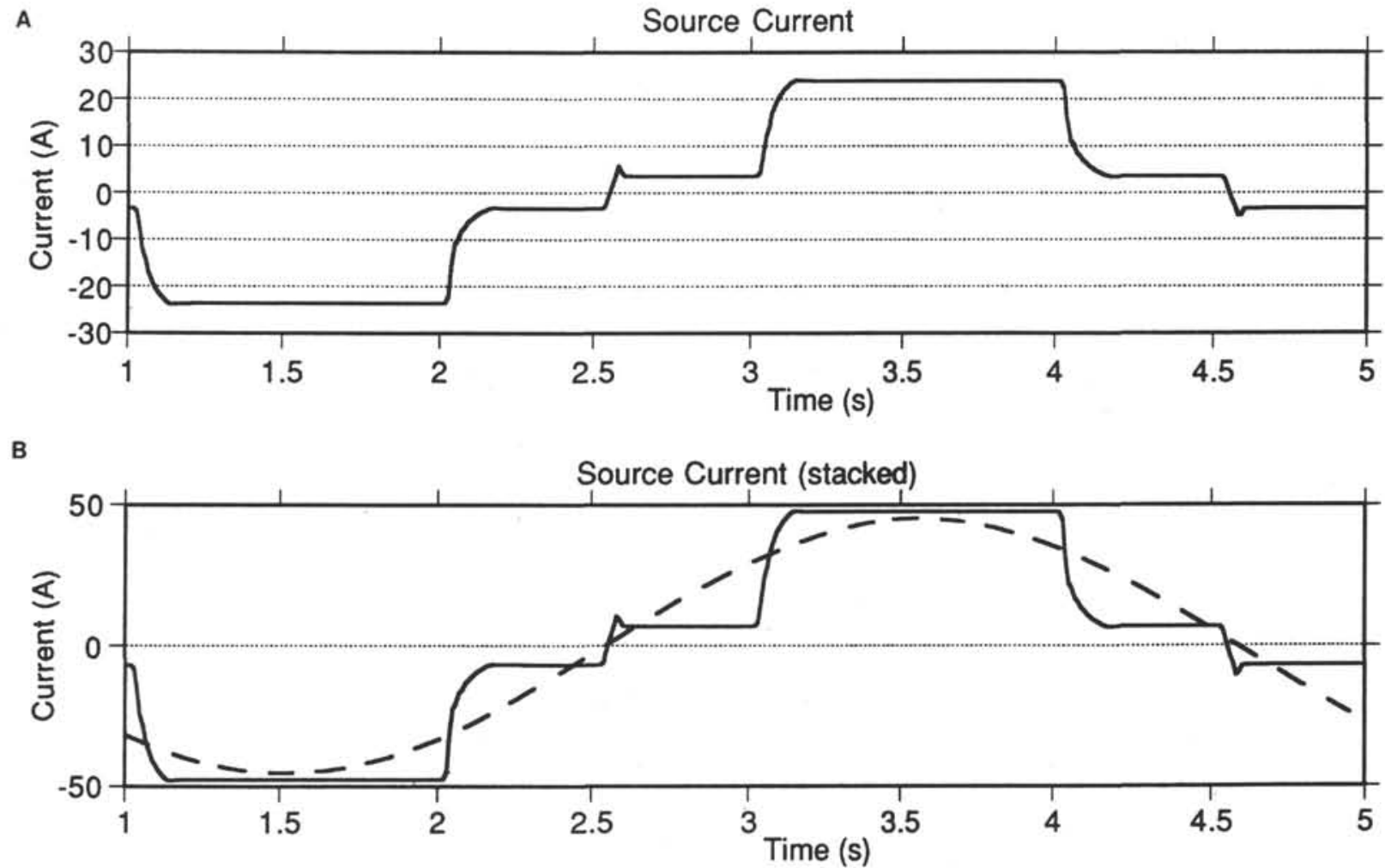

Figure 2. Time variation of the source current. A. Single time series. B. Stacked and folded signal. Dotted curve shows a cosine curve fitted to the signal form.

tudes for Stations 4 and 5 are similar in channel 2. The high amplitude of the noise relative to the fitted cosine curves at these farthest two stations may indicate that the estimated amplitude contains larger errors compared to the closer three stations (8-6).

Observed amplitude of the signals for the two channels can be converted to the electric field by dividing the amplitude by the distances of the two electrode pairs. The distance for Pairs 3 and 5 (channel 1) is $140 \mathrm{~m}$, whereas the distance for Pairs 2 and 4 (channel 2) is $220 \mathrm{~m}$. The results are listed in Table 1 and are shown in Figure 8. If two data points at Stations 1 and 4 are excluded, the electric field ranges from 10 to $300 \mathrm{nV} / \mathrm{m}$.

\section{DISCUSSION}

During Legs 127 and 128, Schlumberger logging was conducted at Site 794. The sedimentary section above the acoustic basement at Site 794 consists of $544 \mathrm{~m}$ of interbedded clay, silty clay, and diatomaceous clay and ooze, with lesser amounts of volcanic ash, tuff, and calcareous, siliceous, and glauconitic clay and claystone. The drilled portion of the basement rocks consists of igneous rocks interbedded by thin sediment layers. Electrical resistivity of the sedimentary section is low compared to open sea sediments and has values between 0.4 and $0.6 \mathrm{ohm}-\mathrm{m}$, which may reflect the high water content of the sediment. The resistivity of the basement section ranges from 1 to $20 \mathrm{ohm}-\mathrm{m}$, where the resistivity in most of this part is confined within 2 and $10 \mathrm{ohm}-\mathrm{m}$, and the geometric mean value is about $5 \mathrm{ohm}-\mathrm{m}$. The logging data indicate that this section extends down to a depth of $750 \mathrm{mbsf}$. The present resistivity experiment was intended to extend the logging depth to several kilometers.

As shown in Figure 1, depths of the five electrodes ranges from 90 to 370 mbsf. All the electrodes are within the top sediment layer at Site 794, which has an average electrical resistivity of $0.5 \mathrm{ohm}-\mathrm{m}$. Channel 1 measures the electric potential difference between 230 and $370 \mathrm{mbsf}$, and channel 2 corresponds to a depth range between 120 and $340 \mathrm{mbsf}$, where the bottom of the sediment layer is at $544 \mathrm{mbsf}$.

Considering the position of the electrodes, the thickness and resistivity of the sediment layer and the longest distance of the present experiment (shown in Fig. 8) suggest that the 5-ohm-m layer extends at least to a depth of several kilometers.

Results of the air-gun survey conducted during Leg 128 (Shinohara et al., this volume) indicate that the top layer of the basement at Site 794 has a $P$-wave velocity of 4.5 to $5.2 \mathrm{~km} / \mathrm{s}$ and a thickness of 2 to $3 \mathrm{~km}$. Because the top of this layer has an electrical resistivity of 2 to $10 \mathrm{ohm}-\mathrm{m}$, on may reasonably assume that the entire top layer has a resistivity of around this value. Note that thin conductive layers on top of the lithosphere are commonly observed on the Pacific and Philippine Sea plates around Japan (Utada et al., 1986). This layer was estimated from the MT measurement of the long-period natural geomagnetic disturbances (longer than $10 \mathrm{~min}$ ). Hence, the total conductance is the only observable parameter (1000 S). Assuming the resistivity value of $10 \mathrm{ohm}-\mathrm{m}$, the thickness of the top conductive layer corresponds to about $10 \mathrm{~km}$. In the Yamato Basin, if one assumes that the 5-ohm-m layer has a thickness of $3 \mathrm{~km}$, total conductance becomes $600 \mathrm{~S}$. Therefore, in this respect, the oceanic lithosphere under the Yamato Basin is similar to the normal oceanic lithosphere. However, MT measurement in the Yamato Basin indicates apparent resistivity values of around $100 \mathrm{ohm}-\mathrm{m}$ for the period range between 10 and $120 \mathrm{~min}$. Because of the top conductive layer, the depth of HCL under the lithosphere shallower than $100 \mathrm{~km}$ cannot explain the MT results in the Yamato Basin. Hence, the deeper part of the lithosphere under the Yamato Basin seems different from the normal oceanic lithosphere. 


\section{REFERENCES}

Becker, K., 1985. Large-scale electrical resistivity and bulk porosity of the oceanic crust, Deep Sea Drilling Project Hole 504B, Costa Rica Rift. In Anderson, R. N., Honnorez, J., Becker, K., et al., Init. Repts. DSDP, 83: Washington (U.S. Govt. Printing Office), 419-427.

Cox, C. S., Filloux, J. H., and Larsen, J. C., 1970. Electromagnetic studies of ocean currents and electrical conductivity below the ocean floor. In Maxwell, A. E. (Ed.), The Sea (Vol. 4, Pt. 2): New York (Wiley-Interscience), 637-693.

Edwards, R. N., Law, L. K., and DeLaurier, J. M., 1981. On measuring the electrical conductivity of the oceanic crust by a modified magnetometric resistivity method. J. Geophys. Res., 86:11609-11615.

Filloux, J. H., 1981. Magnetotelluric exploration of the North Pacific: progress report and preliminary soundings near a spreading ridge. Phys. Earth Planet. Inter., 25:187-195.

Francis, T.J.G., 1982. Large-scale resistivity experiment at Deep Sea Drilling Project Hole 459B. In Hussong, D. M., Uyeda, S., et al., Init. Repts. DSDP, 60: Washington (U.S. Govt. Printing Office), 841-852.
Nobes, D. C., Law, L. K., and Edwards, R. N., 1986. The determination of resistivity and porosity of the sediment and fractured basalt layers near the Juan de Fuca Ridge. Geophys. J. R. Astron. Soc., 87:289-317.

Utada, H., Hamano, Y., and Yukutake, T., 1986. A two-dimensional conductivity model across Central Japan. J. Geomagn. Geoelectr., 38:447-473.

Yukutake, T., Filloux, J. H., Segawa, J., Hamano, Y., and Utada, H., 1983. Preliminary report on a magnetotelluric array study in the Northwest Pacific. J. Geomagn. Geoelectr., 35:575-587.

Date of initial receipt: 21 May 1991

Date of acceptance: 11 March 1992

Ms 127/128B-237
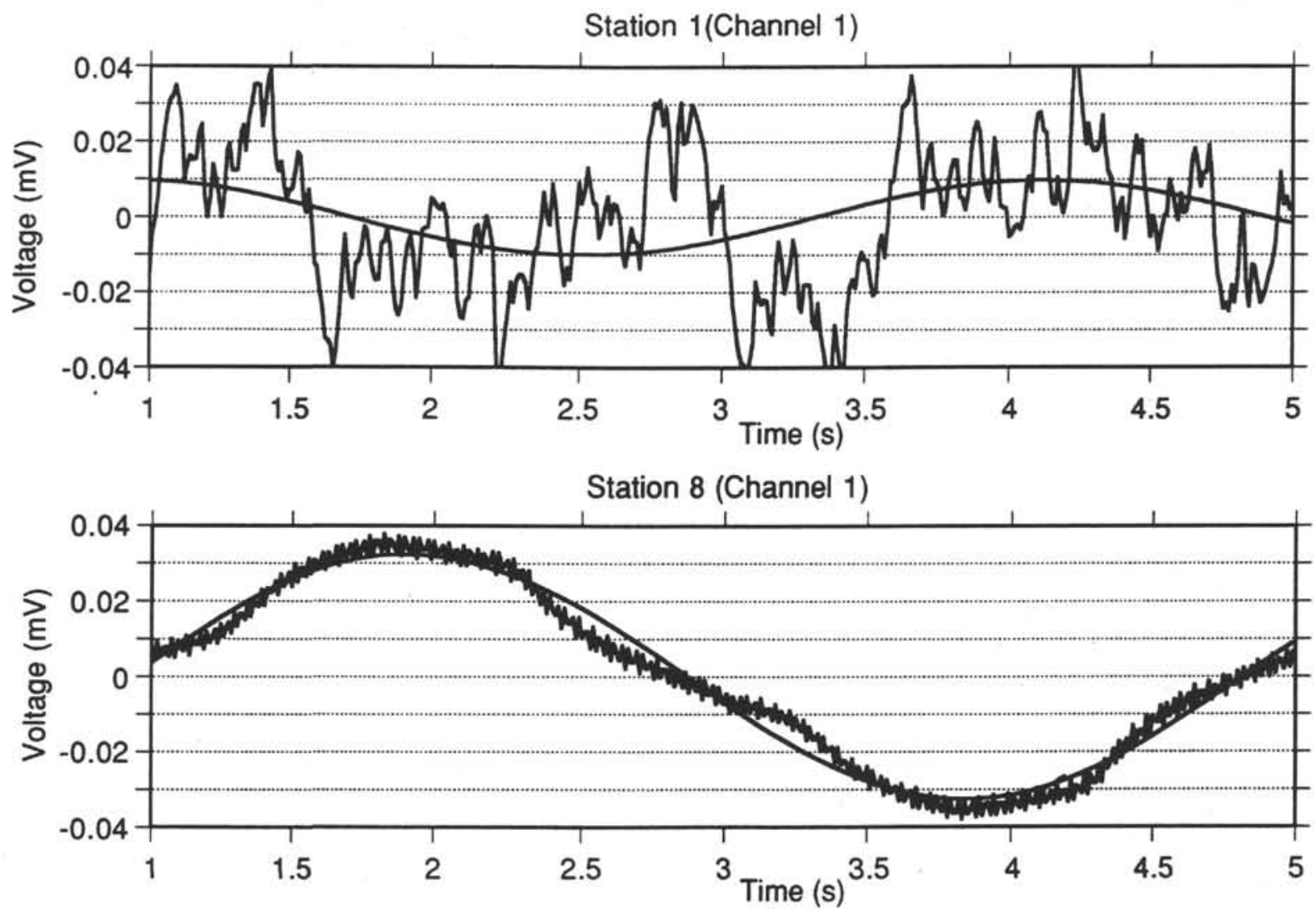

Figure 3. Signal forms observed in channel 1 for Stations 1 and 8 . Vertical scale is in $\mathrm{mV}$. Solid curves show a cosine curve fitted by the least-squared method. 
Station 2 (Channel 1)

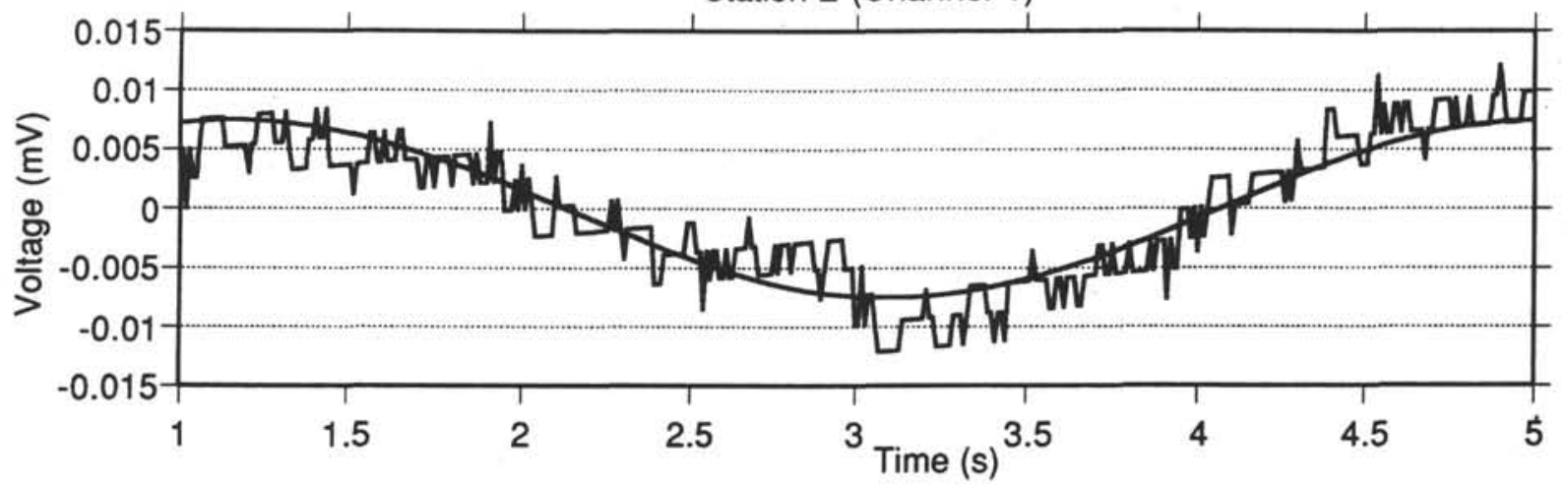

Station 7 (Channel 1)

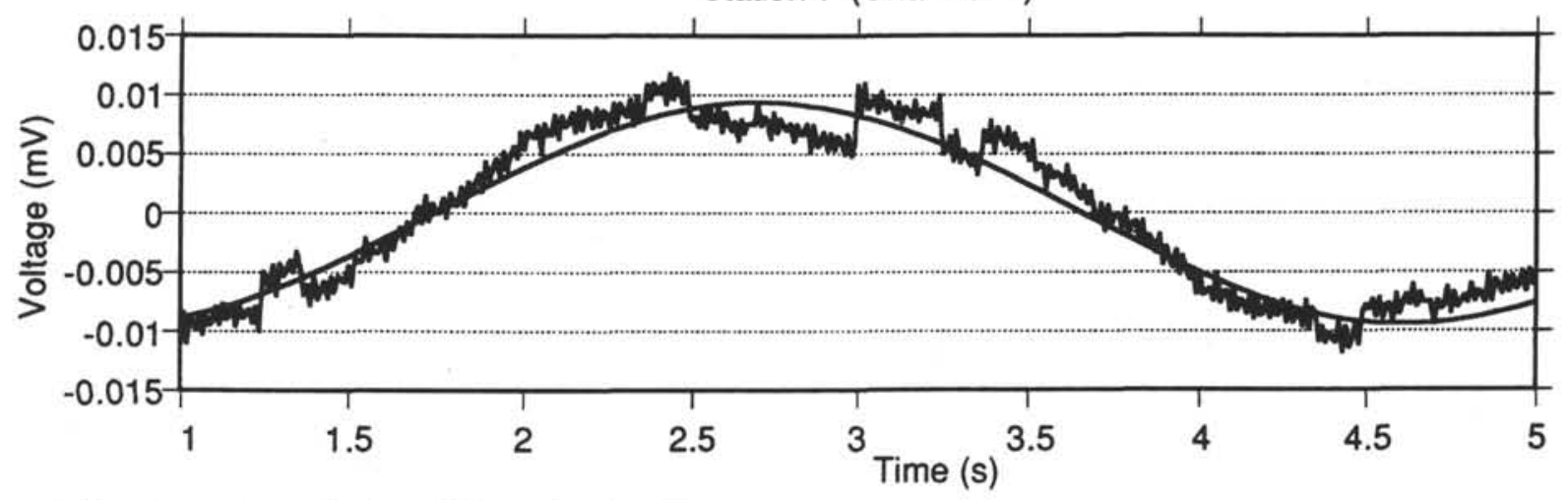

Figure 4. Signal forms observed in channel 1 for Stations 2 and 7.

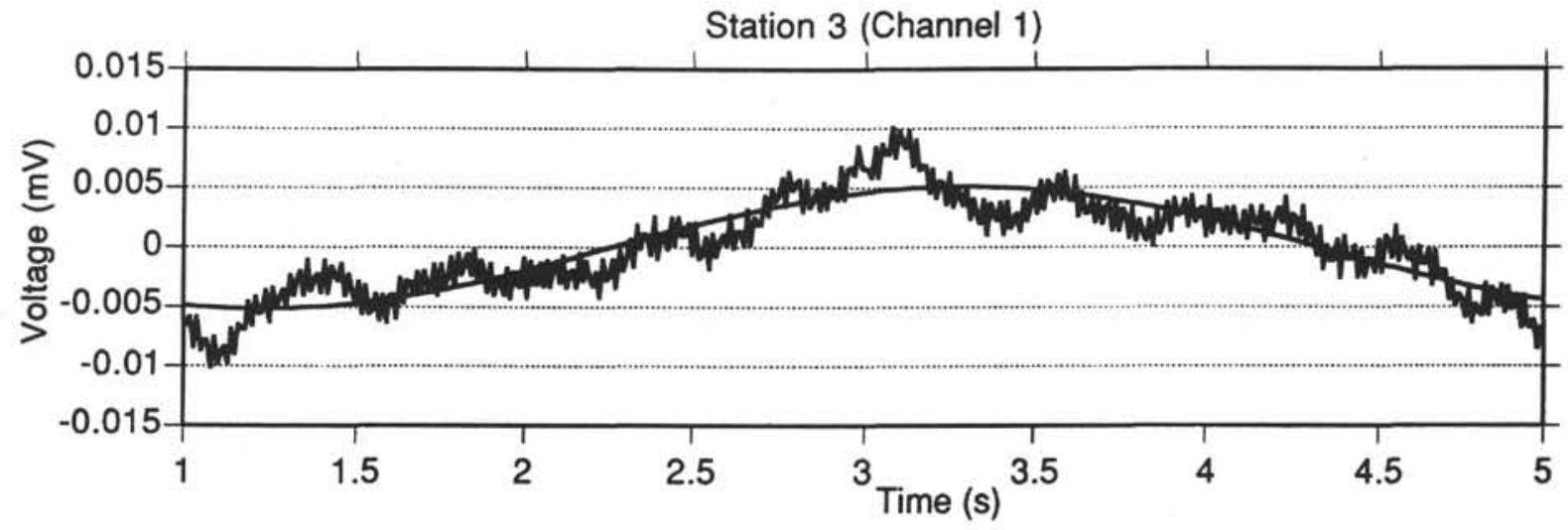

Station 6 (Channel 1)

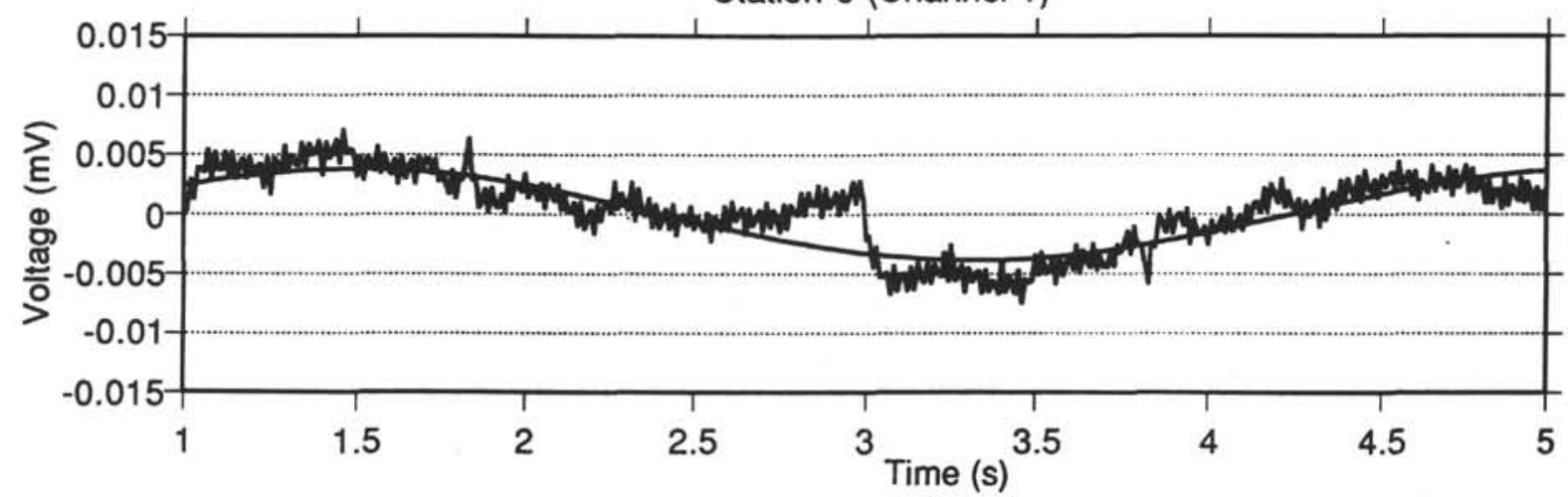

Figure 5. Signal forms observed in channel 1 for Stations 3 and 6. Vertical scale is in $\mathrm{mV}$. 

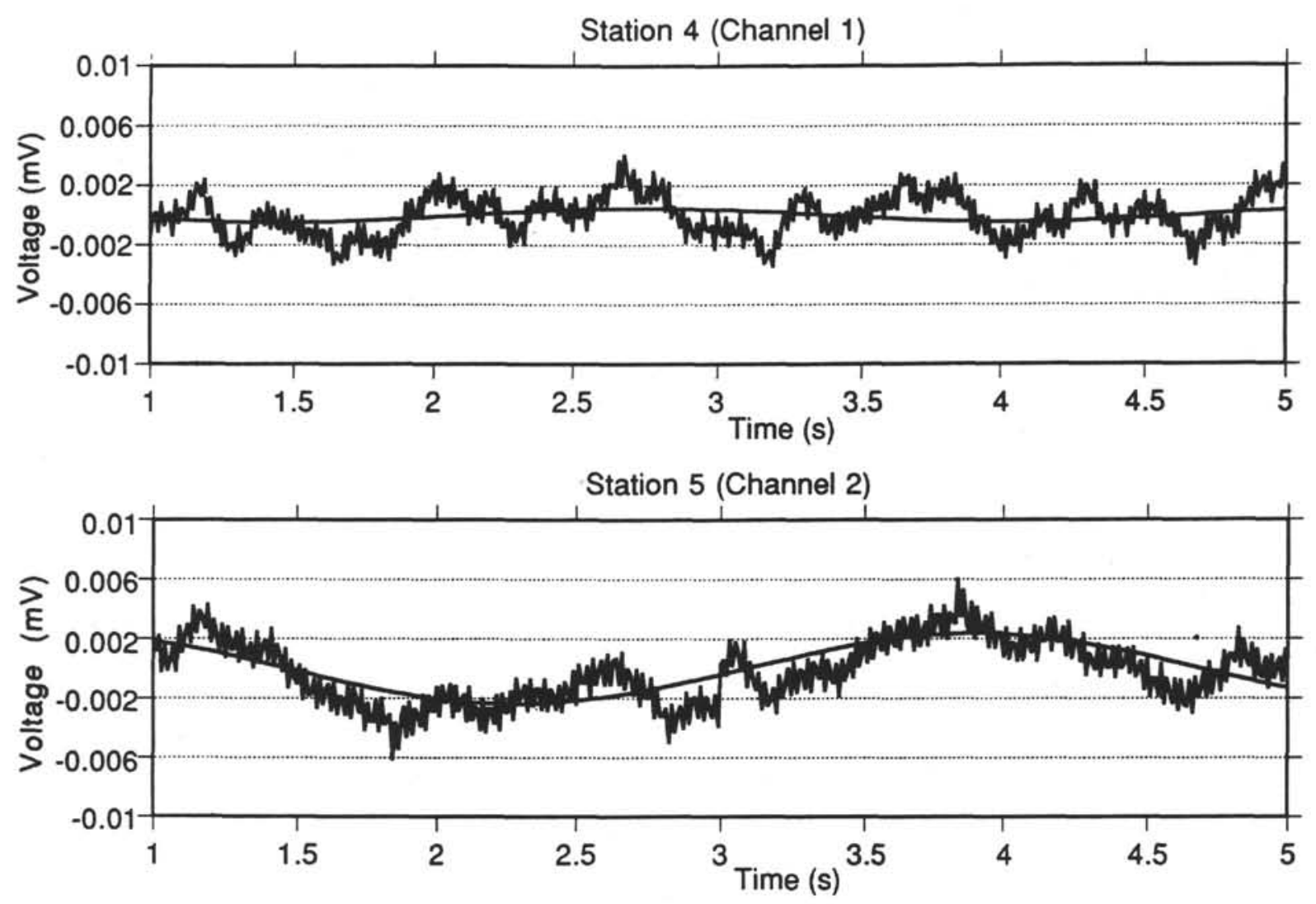

Figure 6. Signal forms observed in channel 1 for Stations 4 and 5 . Vertical scale is in $\mathrm{mV}$. 

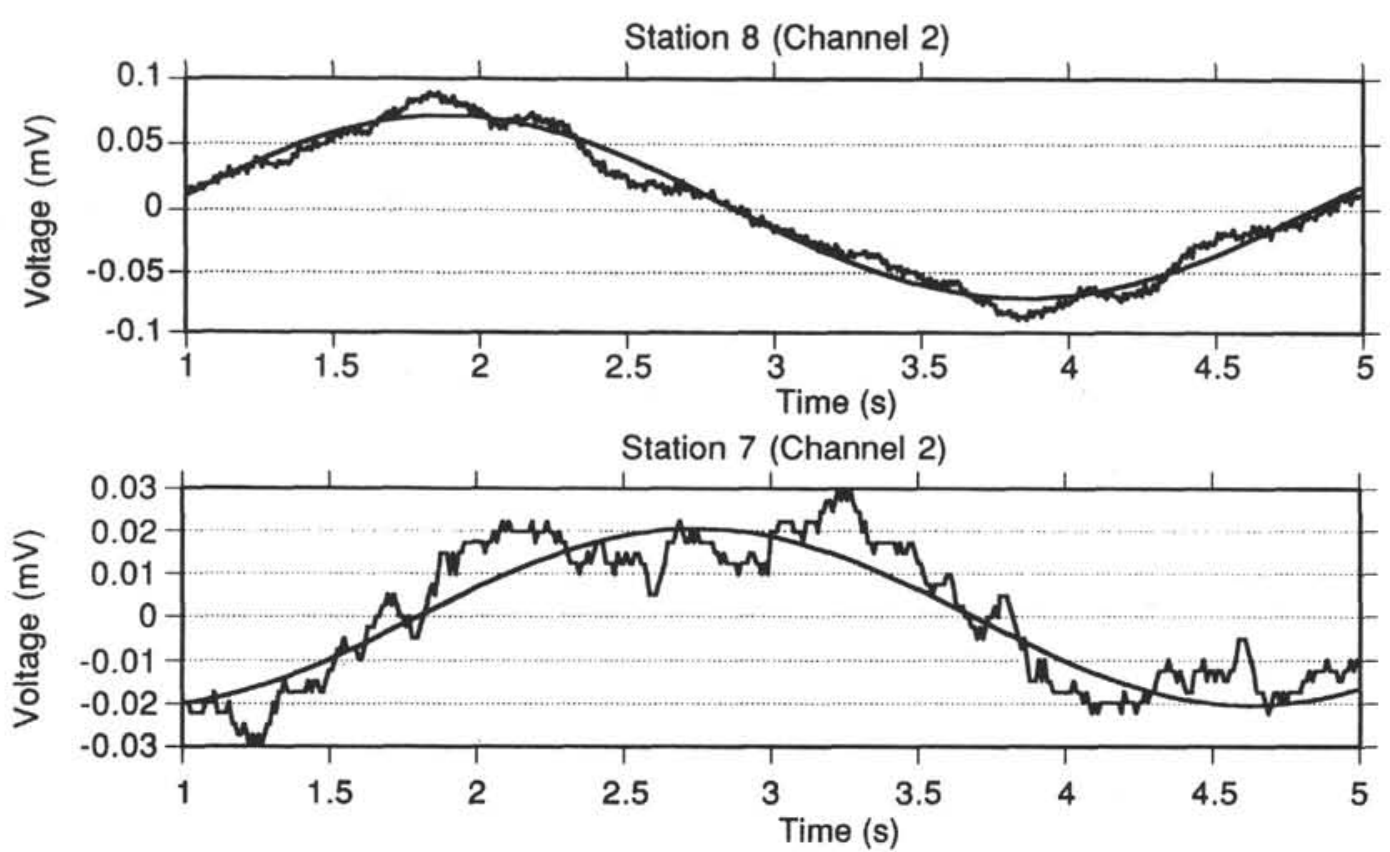

Station 6 (Channel 2)

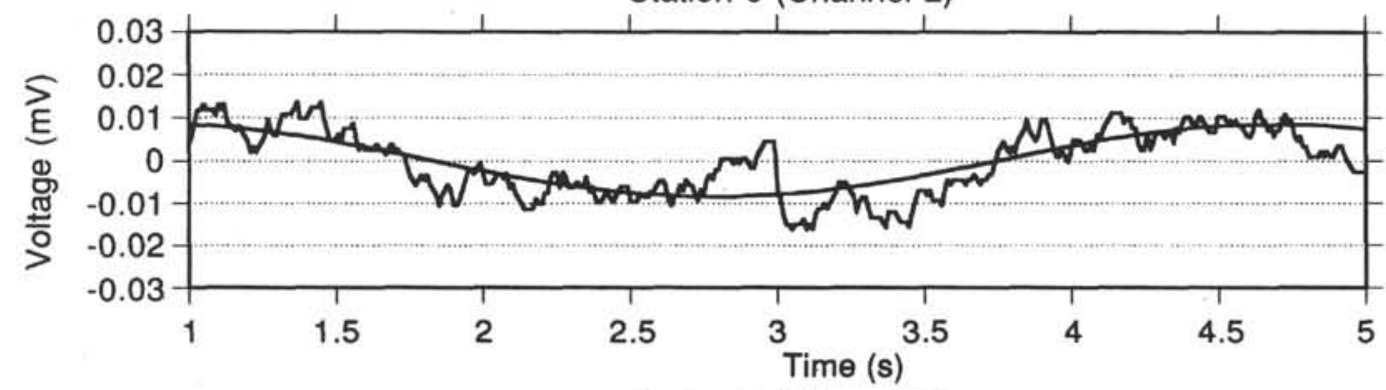

Station 5 (Channel 2)

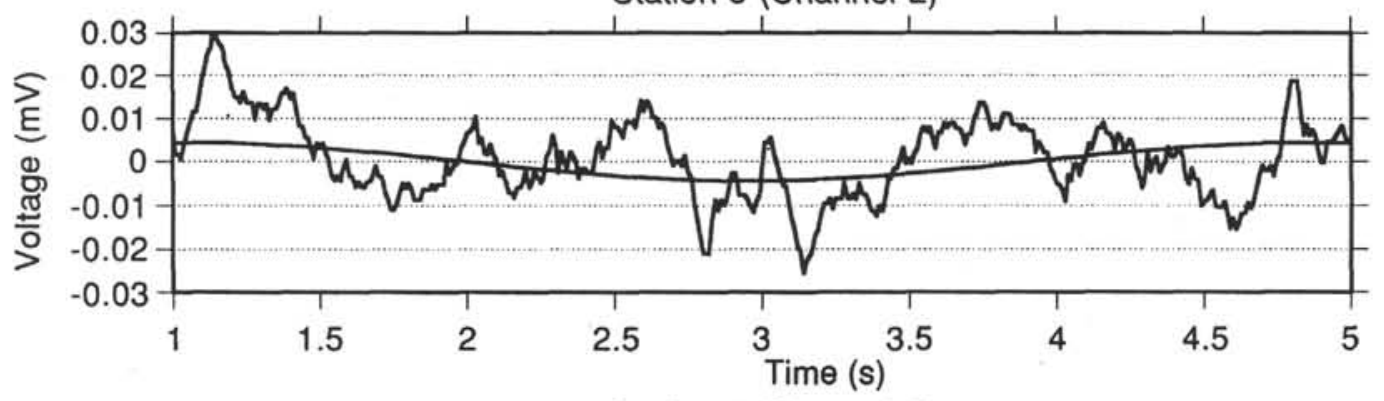

Station 4 (Channel 2)

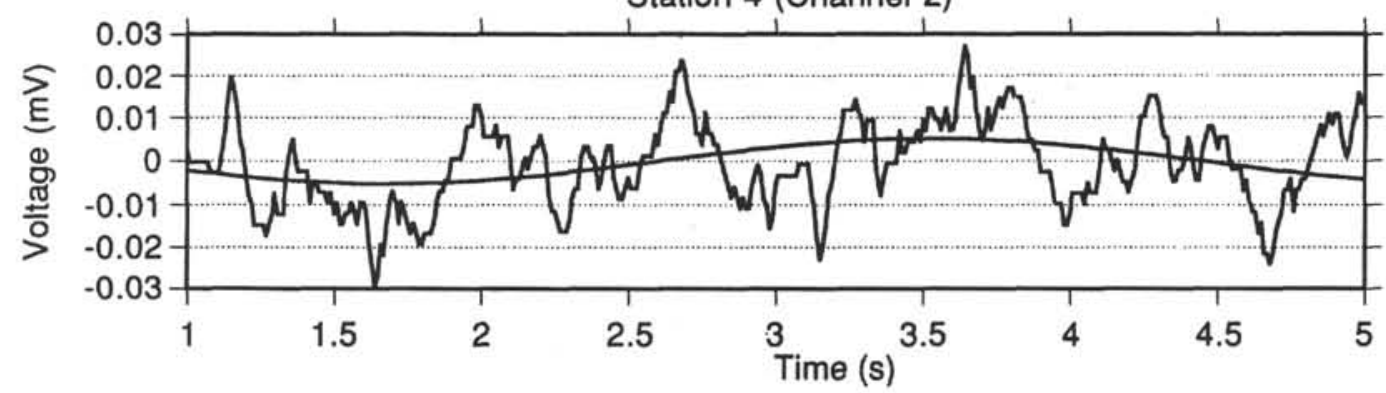

Figure 7. Signal forms observed in channel 2 for Stations 8, 7, 6, 5, and 4. Vertical scale is in $\mathrm{mV}$. 
- Ez (Channel 1)

- Ez (Channel 2)

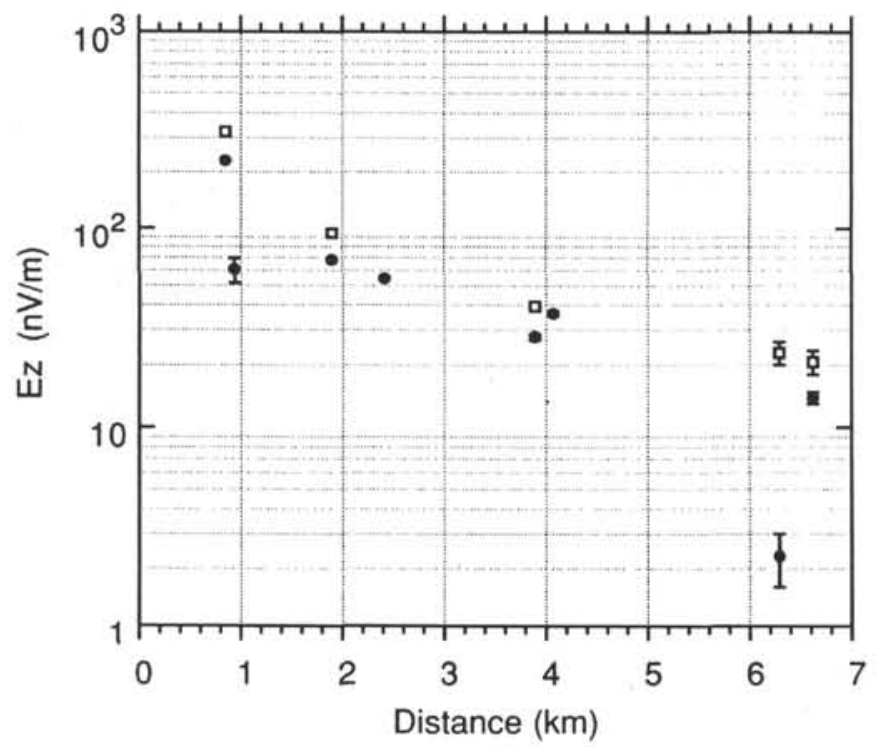

Figure 8. Signal amplitude of the vertical electric field as a function of the source and the receiver distance. 